\title{
International Journal Of Medical And Clinical Case Reports
}

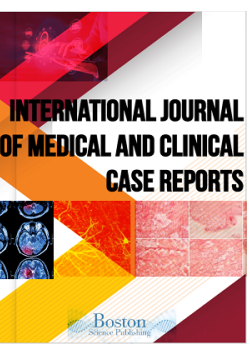

\section{Dengue Unmasking Ulcerative Colitis}

\author{
Dr. M. Rajendran $\odot$, Dr. K. Nagarajan๑”
}

*Post Graduate, Department of General Medicine, Shri Sathya Sai Medical College \& Research Institute, Ammapettai, Tamil Nadu-603108

**Professor, Department of General Medicine, Shri Sathya Sai Medical College \& Research Institute, Ammapettai, Tamil Nadu-603108

\section{A R T I C L E I N F O}

Article history:

Received 30 January 2021

Accepted 22 Febraury 2021

Revised 25 Febraury 2021

Available online 27 February 2021

\begin{abstract}
A $\quad$ B $\quad S \quad T \quad R \quad A \quad C \quad T$
Gastrointestinal manifestations of dengue fever are mainly in the form of Gall bladder wall edema, ascites, transaminitis and rarely GI bleeding. Pre-existing gastrointestinal lesions may bleed during the episode of Dengue. We report a $32 \mathrm{yr}$ old man with dengue fever presenting with lower gastrointestinal bleeding \& colonoscopic features of ulcerative colitis. Dengue fever had unmasked underlying Ulcerative colitis in this patient.
\end{abstract}

(C) 2021, Rajendran M. This is an open-access article distributed under the terms of the Creative Commons Attribution 4.0 International License, which permits unrestricted use, distribution and reproduction in any medium, provided the original author and source are credited

\section{Case Report}

A 32 year old Male, presented with high grade continuous fever for 2 days followed by 30 episodes of fresh bleed per rectum (small quantity 3-5 ml/episode). Bleeding per rectum was associated with lower abdominal pain, occasional loose stools \& feeling of incomplete defecation. He had no significant medical illness in the past. On examination he was febrile, vitals stable and he had signs of dehydration. Systemic examination: CVS - S1, S2 heard no murmurs. RS - NVBS, no additional sounds. Per abdomen - tenderness in the right and left iliac fossa, umbilical region, suprapubic region and he had no organomegaly. Per Rectal examination - Peri-anal skin normal. No fissures. Proctoscopy - Grade 1 internal haemorrhoids noted. No active bleeding [1-8].

Blood investigations on admission: Hb-12.9 g/dl, PCV-39.1, TLC13,200 cu.mm, DC- $\mathrm{P}_{65.5} \mathrm{~L}_{203} \mathrm{M}_{131} \mathrm{E}_{06} \mathrm{~B}_{02}$, Platelet count-57000, ESR-8 mm in 1 hour, RBS, LFT, aPTT \& PT normal, Urea-10 mg/dl, Creatinine-1.09

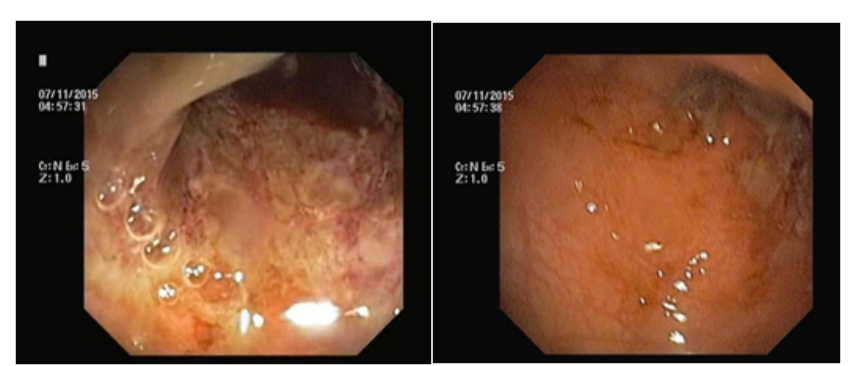

Figures: Colonoscopy Findings mg/dl. Serum electrolytes were normal. HIV, HBsAg, HCV-Non Reactive, ECG-normal, Ultrasound abdomen normal. Stool -RBCs and mucus present, no ova and cyst. Stool culture - Negative for Shigella, Salmonella and E. coli. Dengue Serology: IgM \& IgG (+ve), NS 1 Antigen (-ve); Sigmoidoscopy: Rectum - mild inflammation; Sigmoid - severe mucosal inflammation, granularity and ulcerations present. And mucosa bleeds on touch. Biopsy report: Ulcerative colitis.

\section{Discussion}

Complication of Dengue fever can affect various organs. Gastrointestinal complications like transaminitis, Gall bladder wall edema, and mild to moderate ascites are common. Cardiovascular and neurological complications can also occur. Some can manifest with melena due to upper GI bleed. Here we present a case of hematochezia due to bleeding from Ulcerative colitis lesions in sigmoid colon provoked by severe thrombocytopenia due to dengue.

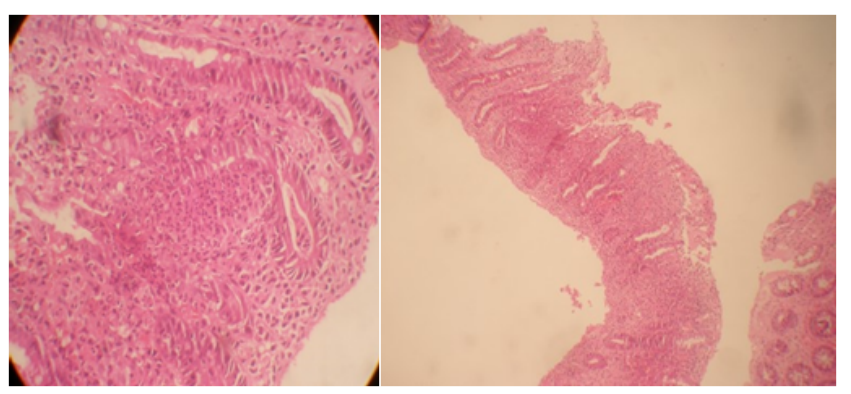

Figures: Histopathology Finding

Corresponding author

M. Rajendran, Post Graduate, Department of General Medicine, Shri Sathya Sai Medical College \& Research Institute,

Ammapettai, Tamil Nadu- 603108

E-mail address: rajendranm2255@gmail.com 
M. Rajendran, et al. / International Journal of Medical And Clinical Case Reports

\section{Conclusion}

Any unusual bleeding in thrombocytopenia, think also of other structural causes.

\section{Acknowledgement}

We thank anonymous referees for thie ruseful suggestions.

\section{Conflict Of Interest \\ None}

Ethical Approval

None

\section{Source of Funding}

None

\section{References}

1. Park S. Results of the National Infectious Diseases Surveillance, 2013. Public Health Weekly Rep 2014;7:881-7. [Google Scholar]

2. Park JH, Lee DW. Dengue fever in South Korea, 2006-2010. Emerg Infect Dis 2012;18:1525-7. [PMC free article] [PubMed] [Google Scholar]
3. Ghosh A, Dar L. Dengue vaccines: challenges, development, current status and prospects. Indian J Med Microbiol 2015;33:3-15. [PubMed] [Google Scholar]

4. Halstead SB. Dengue. Lancet 2007;370:1644-52. [PubMed] [Google Scholar]

5. HenterJI,HorneA,AricóM, etal.HLH-2004:diagnostic and therapeutic guidelines for hemophagocytic lymphohistiocytosis. Pediatr Blood Cancer 2007;48:124-31. [PubMed] [Google Scholar]

6. Imashuku S, Ueda I, Teramura T, et al. Occurrence of haemophagocytic lymphohistiocytosis at less than 1 year of age: analysis of 96 patients. Eur J Pediatr 2005;164:315-9. [PubMed] [Google Scholar]

7. Risma KA, Frayer RW, Filipovich AH, et al. Aberrant maturation of mutant perforin underlies the clinical diversity of hemophagocytic lymphohistiocytosis. J Clin Invest 2006;116:182-92. [PMC free article] [PubMed] [Google Scholar]

8. Katano H, Cohen JI. Perforin and lymphohistiocytic proliferative disorders. Br J Haematol 2005;128:739-50. [PubMed] [Google Scholar]

Submit your manuscript to Boston science publishing journal and benifit from:

- Convenient online submission

Rigorous peer review

- Immediate publication on acceptance

Open access: articles freely available online

High visibility within the field

- Retaining the copyright to your article 